\title{
Development and Performance of a Mechanical Egg Collection System Versus the Hand-Operated Dutch Nest

\section{-Author(s)}

\section{Pilotto $F^{1}$}

Ribeiro AML"

Cargnelutti Filho A"

Klein VA'

School of Agronomy and Veterinary Medicine (FAMV), Universidade de Passo Fundo (UPF), Campus Universitário São José, CEP 99001-970 - Passo Fundo, RS Brasil

" Department of Animal Science, Graduate Program, Universidade Federal do Rio Grande do Sul (UFRGS), Av. Bento Gonçalves 7712, CEP: 91540-000, Porto Alegre, RS, Brasil.

III Center for Rural Sciences - Department of Plant Science, Universidade Federal de Santa Maria (UFSM), Avenida Roraima s/n, Campus Camobi, CEP 97105-900 - Santa Maria, RS - Brasil

\section{-Mail Address}

Corresponding author e-mail address F. Pilotto

Estrada Casanova, 383, Condomínio Morada Além do Horizonte, Ipês, 403, Vila Mattos, CEP: 99064-415, Passo Fundo RS - Brasil.

Phone: (54) 92137690

Email: fernandopilotto@upf.br

\section{-Keywords}

Broiler breeders, laying behavior, mechanical nest.

\section{ABSTRACT}

The aim of this study was to design a new mechanical nesting system based on scientific works on the behavior of laying hens, and to compare its performance with that of a hand-operated Dutch nest. The equipment was assessed in two poultry houses; in the first one, the eggs were collected manually, whereas in the second one, the newly designed mechanical nest was used for the collection. A total of 7,800 hens and 800 males were housed in each poultry house, and the percentages of eggs produced, nest dirty eggs, floor eggs, and cracked and discarded eggs were determined between weeks 25 and 52 . The percentage of eggs with microcracks, infertility, embryo mortality, bacterial contamination, fungal contamination, chicks with stunting syndrome and hatching from both types of nest was assessed in the hatchery on a fortnightly basis. The mechanical nest designed herein proved to be a good alternative to the hand-operated Dutch nest, but it still has to be improved in order to have the same performance, especially with regard to reduction in the incidence of floor eggs.

\section{INTRODUCTION}

Consumers have been increasingly demanding the poultry industry to adopt measures that respect poultry welfare during breeding (Costa et. al, 2012). The development of mechanical nests that are well accepted by the hens to lay the eggs has been a great challenge for the poultry industry (Elson, 2010). Broiler breeders cultivate an array of habits from their ancestors and develop new ones as they are genetically selected or exposed to new environments (Shimmura et. al, 2015). Huber et al. (1985) classified the behavior of laying hens into four stages. In Stage 1, the laying hens are separated from the flock; after that, they look for a nesting site and explore it. In Stage 2 , the hens enter the nest, scratch it with their feet and peck at the floor, make rotating movements in a circle and then rest in silence. In Stage 3, they contract their chests ("penguin position") and lay the egg. Finally, in Stage 4, they roll the egg under their bellies using their beaks, sit on it, rest in silence, and then leave the nest. Nest acceptance by hens depends a series of factors such as genetic selection (Lay et al., 2011), housing and breeding management conditions (Oliveira et. al, 2010), production management practices (Decuypere et al., 2010), and on the type of nest. Hens prefer nests with a concave bottom (Brake, 1985), filled with wood shavings (Holcman et al., 2007), single nests (Peterson, 1989), enclosed nests (Appleby \& McCrae, 1986), gray or brown-colored nests (Brake, 1993), nests located near the floor (Hurnik et al., 1973), with rectangular wooden perches (Appleby et al., 1992; Scholz et al, 2014) and which allow for the maintenance of eggs in the nest after laying (Kite et al., 1980). The hand-operated Dutch nesting system yields a good performance because it has most of the features 
that are attractive to hens, unlike mechanical nests, which have a flat bottom lined with a plastic nest pad, are often multi-bird units and do not allow for the maintenance of eggs in the nest after laying. Therefore, the present study sought to design a mechanical nest that could include the features that are most attractive to hens when it comes to egg laying and to compare the performance of this type of nest with the handoperated one.

\section{MATERIAL AND METHODS}

The study was carried out in two stages. The new nest type was designed in the first stage, and the comparison of this new nest type with the handoperated Dutch type was made in the second stage. The mechanical nest was designed in modules. Each module contains 24 nests (12 upper nests and 12 lower nests, six on each side of the equipment), at two heights (Figure 1).

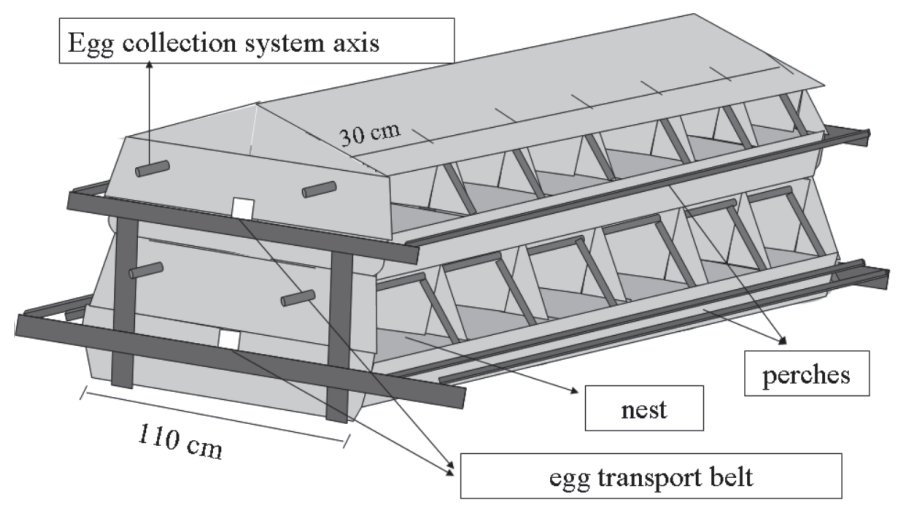

Figure 1 - Mechanical nest designed (module with 24 nests).

The nests were $30 \mathrm{~cm}$ wide, $25 \mathrm{~cm}$ high, and $50 \mathrm{~cm}$ deep. In order to allow easy access of hens, perches were installed at 20 and $55 \mathrm{~cm}$ from the floor in the upper front and lower front of the module, respectively. The transportation of eggs from the nests to the collecting belts, located at the center of the module, both in the upper and lower nests, was effected by a system consisting of a comb-like structure supported by two rods attached to a longitudinal axis mounted in the upper nests. This axis, when rotated, moves the comb positioned at the entrance of the nest in a swinging direction, transporting the eggs onto the collecting belt. After the eggs are delivered onto this belt, the axis is rotated in the reverse direction, causing the collecting comb to return to its initial position. Four of these systems were designed for each module, one for each row of nests, two in the upper compartment, and two in the lower one. At the nest entrance, we designed a hole opening for the eggs laid by hens during the travel of the collecting comb. Thus, when the collecting comb returns to its initial position, the eggs are conveyed up to the hole opening where they are rolled over again to the center of the nest to be collected in the next round. A rear partition (Figure 2) was placed in order to prevent the hens from seeing the eggs on the transport belt.

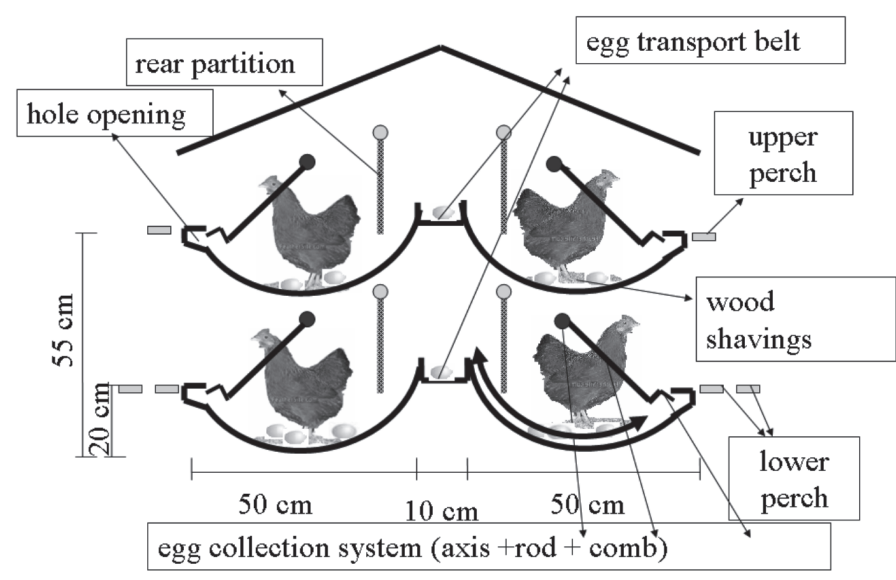

Figure $\mathbf{2}$ - Operation of the designed mechanical nest.

The modules were placed longitudinally at the center of the poultry house, and were connected into a single column. A motor coupled to a reducer was placed for each set of 10 modules for rotation of the collecting system axes. Egg transportation onto the collection table, from the lower and upper nests, is accomplished by the same conveyor belt. In this case, the eggs from the lower nests are transported to the last module (in the opposite direction of the collection table), where they are taken to the upper nests by a parallel belt and conveyed along with the eggs from the nests located in the upper compartment of the module onto the collection table (Figure 3).

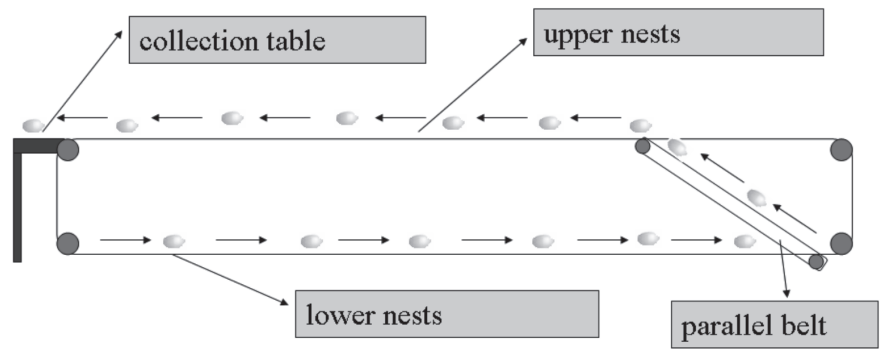

Figure 3 - Egg transport belt in the desigend mechanical nest.

The Dutch nest, which was made of wood, had 24 nests in each module, 12 upper nests and 12 lower nests, six on each side, at two heights. The nests in the upper compartment were placed $100 \mathrm{~cm}$ from the floor, whereas those in the lower compartment were placed $50 \mathrm{~cm}$ above the floor. Dutch nests were $30 \mathrm{~cm}$ wide, $25 \mathrm{~cm}$ high, and $27.5 \mathrm{~cm}$ deep (Figure 4). 


\section{Development and Performance of a Mechanical Egg Collection System Versus the Hand-Operated Dutch Nest}

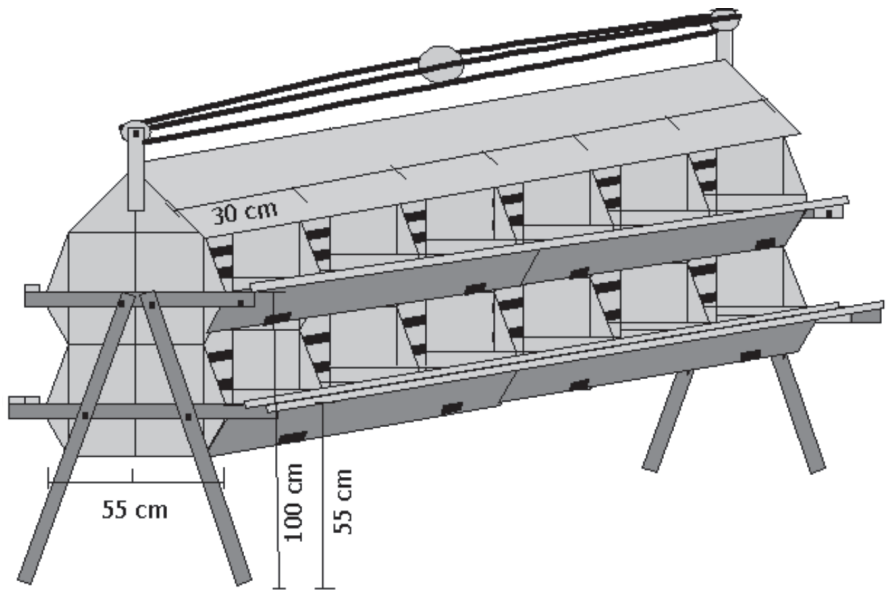

Figure 4 - Hand-operated Dutch nest model.

In order to allow placing the mechanical nest longitudinally to the center of the poultry house, the position of the feeding and drinking troughs had to be changed, compared with the hand-operated nesting system, as shown in Figure 5.

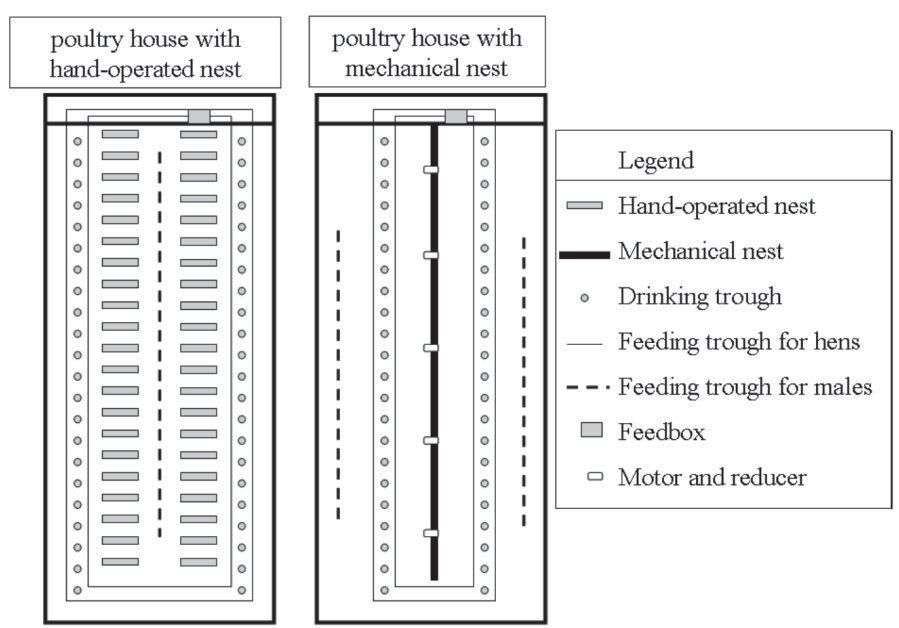

Figure $\mathbf{5}$ - Position of equipament in the poultry house with mechanical and hand-operated nests.

The performance of both types of nests was compared on a broiler breeder farm with two samesized poultry houses and identical solar orientation. In one of the poultry houses, the eggs were collected mechanically whereas in the other house, the collection was made manually.

In each poultry house, 7,800 hens and 820 males of the Cobb 500 line with 22 weeks of age and derived from the same breeding farm were housed. Seventy modules, each with 24 nests, were installed in the poultry house with the hand-operated nesting system, and 50 modules, each with 24 nests, were installed in the poultry house equipped with the mechanical collection system. The smaller number of nests with mechanical egg collection was due to the fact that the 50 modules occupied the whole length of the poultry house. Therefore, in order to keep the same economic feasibility of the poultry house with the mechanical nests, compared to the hand-operated nests, the same number of hens was housed in both systems, consequently allowing for more hens per nest in the poultry house equipped with mechanical egg collection.

The performance of the mechanical and handoperated collection systems was assessed during the period of 25 and 52 weeks of life, with a weekly comparison of the percentages of eggs produced, floor eggs, cracked eggs, nest dirty eggs, and discarded eggs. The percentage of eggs produced every week was calculated by dividing the number of eggs laid during the week by the number of hens, whereas the weekly percentage of floor eggs, cracked eggs, nest dirty eggs, and discarded eggs was calculated by dividing the number of these eggs by the total number of eggs produced. Nest dirty eggs were those whose shell surface had feces on it; cracked eggs were those with cracks in their shells; and discarded eggs were those whose shell was completely broken, causing leaking of the egg yolk and white.

The eggs were collected five times a day in both systems and the data were registered on a daily basis. Floor eggs were collected 10 times a day in both systems. Housing conditions and management practices were exactly the same in both poultry houses. Wood shavings were replaced every 15 days in the hand-operated and mechanical nests.

In the hatchery, 344 hatching eggs from each type of nest were visually assessed fortnightly in order to determine the percentage of eggs with microcracks in their shells. These eggs were later incubated for the assessment of fertility; of embryo mortality at 0 to 7 , 8 to 14,15 to 18 and 19 to 21 days of incubation; of eggs contaminated by bacteria or fungi; of chicks with stunting syndrome; and of hatching from both collection systems. Hatching eggs were those which had no flaws or cracks in their shells, no double yolk, and weight greater than $48 \mathrm{~g}$. Eggs with microcracks were those with small cracks in their shells. These cracks usually appear after acclimation and affect moisture loss by the eggs during the incubation period. Fungal contamination was identified by the presence of fungal colonies visible to the naked eye on the air cell membrane when the eggs were broken out. Bacterial contamination was determined by the presence of bacterial culture leaking out of eggshell pores and by the foul smell given off at the time when the eggs were broken out to determine embryonic death. Fertility and mortality between 0 
and 7 days of incubation were tested by candling, and breakout examination of clear eggs was performed on incubation day 12 . The remaining data were assessed at hatch by counting the number of live chicks and by breaking out unhatched eggs.

Performance data were assessed by the analysis of variance, considering a randomized block design in 2 x 28 factorial arrangement, with split plots. The main plot comprised both types of nests (poultry house with mechanical nest and poultry house with handoperated nest), whereas the subplot included the 28 weeks of evaluation. The Student's t test was used to assess hatchery data, with a 5\% significance level. All statistical analyses were performed using the SAS software.

\section{RESULTS AND DISCUSSION}

\section{Mechanical Nest Design}

The mechanical nest design was based on the observation of the laying behavior of farm hens and on the results of scientific studies conducted by different authors (Hurnik et al., 1973; Kite et al., 1980; Brake, 1985; Appleby \& McCrae, 1986; Peterson, 1989; Appleby et al., 1992; Brake, 1993; Holcman et al., 2007). The first question raised before designing the equipment was "why do hens show a greater rejection of commercially available mechanical nests than of hand-operated ones?" The main difference between these nests is the type of bedding used. The floor of hand-operated nests are covered with wood shavings, which provides more comfort and allows keeping the eggs in the nest after laying, whereas mechanical nest floors are fitted with plastic pads, which are slightly sloped so that the eggs roll onto the transport belt after laying in order to be mechanically collected. Hens, although reared in a confined environment, maintain several behaviors that were passed on from their ancestors (Shimmura et al., 2015) and, just as other bird species, they build a nest in which to lay their eggs and hatch them, with the aim of perpetuating their species (Moller et al., 2014). Huber et al. (1985), after observing laying behavior, reported that hens pull the laid eggs under their bellies. This behavior is easily observed on broiler breeder farms when hens, on entering the nest, roll all of the eggs already in the nest under their bellies with their beaks prior to laying the next egg, clearly demonstrating their intention to hatch them (personal observation). Another important aspect to take into account is the provision of wood shavings in the nest, which provides hens with greater comfort than plastic pads and allows them to easily hollow out a nest through rotating movements in a circle prior to laying. Duncan et al., (1989) noted that domestic hens prefer to lay in nests containing loose material that can be both molded by their body and by feet movements, and manipulated with their beaks during nest building.

The following factors were also considered in the design of the mechanical nest: nest height, nest size, enclosure, nest color, perch shape, sanitation, and ease of operation:

- Nest height: the closer the nests are to the floor, the more attractive they are to hens. Hurnik et al. (1973) provided hens with nests at 78 and $48 \mathrm{~cm}$ from the floor, and observed that out of the total number of eggs laid in the nest, $84 \%$ were laid in the nests placed at $48 \mathrm{~cm}$. Some current broiler breeder flocks selected for higher breast muscle gain have shown greater difficulty entering the nests. This encourages floor laying, especially at the end of the laying period when they are heavier and have fewer feathers. In order to minimize this problem, some breeders have sought to reduce nest height, but this practice increases the number of employees with back problems caused by the greater physical effort required for egg collection. In the mechanical nest, built to facilitate the access of hens to the nesting site, the first row of nests is $20 \mathrm{~cm}$ from the floor while the second row is $55 \mathrm{~cm}$ from the floor;

- Nest size: the use of community nests is not recommended (MAFF, 1982). Peterson (1989) found that $79 \%$ of the hens preferred to lay their eggs in single nests while $14 \%$ preferred community nests. The mechanical nests were designed as single units and were $30 \mathrm{~cm}$ wide, $50 \mathrm{~cm}$ deep, and $25 \mathrm{~cm}$ high. The width and height of the hand-operated Dutch nest is the same as that of the mechanical nest, but the depth is twice as large. Disregarding the nest areas with larger concavity, the depth of the nest filled with wood shavings was approximately $38 \mathrm{~cm}$;

- Enclosure: Appleby \& McCrae (1986) observed that the more enclosed the nest, the more attractive it was to laying hens. Therefore, to increase the enclosure of the designed mechanical nest and to prevent hens from seeing the eggs being carried along the collecting belt, a cotton-cloth partition wall was placed $10 \mathrm{~cm}$ away from the back of the nest.

- Nest color: Hurnik et al. (1973) and Brake (1985) analyzed the influence of nest color on laying behavior and found out that hens prefer unpainted nests, with metallic or natural wood color, to nests painted black, 
blue, green, yellow, or red. The following materials were used to build the mechanical nest: galvanized metal plate, gray iron bars, wooden perches, and a brown cotton cloth partition wall;

- Perch shape: Duncan et al. (1992) noted that rectangular perches were more widely used by caged laying hens than circular perches. As to the type of material, Miuri et al. (1990) and Appleby et al. (1992) verified that hens prefer wooden and wire perches to plastic ones. Rectangular wooden perches measuring $8 \mathrm{~cm}$ in width and $2 \mathrm{~cm}$ in thickness were built for the two nest heights;

- Sanitation: the use of easy-to-clean equipment reduces the number of employees in charge of cleaning and warrants good disinfection (Sander et al., 2003). For the construction of the mechanical nest, metal materials, which make cleaning and disinfection easier, were used, except for the wooden perches;

- Ease of operation: the nests were designed in modules in order to be easily assembled and disassembled on the farms to allow proper good cleaning and disinfection practices on the farm, as it is necessary to remove the nesting equipment during downtime.

\section{Zootechnical Assessment of the Designed Mechanical Nest}

The weekly percentages of eggs produced, nest dirty eggs, and cracked eggs were similar between the poultry house with mechanical nests and that with hand-operated nests in most of the assessed weeks ( $p>0.05)$ (Table 1). However, the mean values

Table 1 - Zootechnical results obtained for the poultry house with hand-operated and mechanical egg collection during 28 weeks of assessment

\begin{tabular}{|c|c|c|c|c|c|c|c|c|c|c|}
\hline & \multicolumn{2}{|c|}{$\%$ of eggs produced } & \multicolumn{2}{|c|}{$\%$ of nest dirty eggs } & \multicolumn{2}{|c|}{$\%$ of floor eggs } & \multicolumn{2}{|c|}{$\%$ of cracked eggs } & \multicolumn{2}{|c|}{$\%$ of discarded eggs } \\
\hline weeks & $\begin{array}{l}\text { Hand- } \\
\text { operated } \\
\text { nest }\end{array}$ & $\begin{array}{l}\text { Mechanical } \\
\text { nest }\end{array}$ & $\begin{array}{l}\text { Hand- } \\
\text { operated } \\
\text { nest }\end{array}$ & $\begin{array}{l}\text { Mechanical } \\
\text { nest }\end{array}$ & $\begin{array}{l}\text { Hand- } \\
\text { operated } \\
\text { nest }\end{array}$ & $\begin{array}{l}\text { Mechanical } \\
\text { nest }\end{array}$ & $\begin{array}{l}\text { Hand- } \\
\text { operated } \\
\text { nest }\end{array}$ & $\begin{array}{l}\text { Mechanical } \\
\text { nest }\end{array}$ & $\begin{array}{l}\text { Hand- } \\
\text { operated } \\
\text { nest }\end{array}$ & $\begin{array}{c}\text { Mechanical } \\
\text { nest }\end{array}$ \\
\hline 25 & $12.2^{b}$ & $23.6^{a}$ & $2.4^{b}$ & $3.8^{a}$ & $24.0^{a}$ & $19.3^{b}$ & $0.7^{a}$ & $0.6^{b}$ & $1.3^{\mathrm{a}}$ & $0.7^{\mathrm{b}}$ \\
\hline 26 & $37.1^{\mathrm{b}}$ & $47.4^{\mathrm{a}}$ & $2.2^{b}$ & $3.3^{\mathrm{a}}$ & 14.3 & 13.7 & 0.5 & 0.45 & 0.6 & 0.6 \\
\hline 27 & 59.4 & 61.5 & $2.7^{b}$ & $4.6^{\mathrm{a}}$ & $7.6^{b}$ & $14.6^{\mathrm{a}}$ & 0.4 & 0.5 & $0.4^{b}$ & $0.5^{\mathrm{a}}$ \\
\hline 28 & 73.1 & 70.5 & $2.6^{b}$ & $3.7^{\mathrm{a}}$ & $3.2^{b}$ & $10.4^{\mathrm{a}}$ & $0.4^{b}$ & $0.5^{\mathrm{a}}$ & $0.4^{b}$ & $0.5^{\mathrm{a}}$ \\
\hline 29 & $80.2^{\mathrm{a}}$ & $76.9^{b}$ & $2.0^{\mathrm{b}}$ & $3.2^{\mathrm{a}}$ & $2.5^{b}$ & $10.3^{a}$ & $0.3^{b}$ & $0.6^{\mathrm{a}}$ & $0.4^{b}$ & $0.5^{\mathrm{a}}$ \\
\hline 30 & $82.4^{a}$ & $77.7^{\mathrm{b}}$ & 2.1 & 3.0 & $2.8^{\mathrm{b}}$ & $7.5^{\mathrm{a}}$ & 0.4 & 0.5 & 0.4 & 0.4 \\
\hline 31 & 83.5 & 80.9 & 2.5 & 2.8 & $2.5^{b}$ & $6.0^{\mathrm{a}}$ & 0.4 & 0.4 & 0.4 & 0.4 \\
\hline 32 & $82.2^{\mathrm{a}}$ & $79.1^{\mathrm{b}}$ & 2.5 & 2.5 & $2.4^{\mathrm{b}}$ & $5.1^{\mathrm{a}}$ & 0.4 & 0.4 & 0.4 & 0.4 \\
\hline 33 & 81.6 & 79.3 & 2.0 & 2.4 & $2.2^{\mathrm{b}}$ & $5.7^{\mathrm{a}}$ & 0.4 & 0.5 & 0.4 & 0.4 \\
\hline 34 & 79.4 & 79.0 & 2.9 & 2.4 & $1.8^{\mathrm{b}}$ & $5.1^{\mathrm{a}}$ & 0.4 & 0.5 & 0.4 & 0.4 \\
\hline 35 & 78.2 & 77.1 & 2.4 & 2.3 & $2.1^{b}$ & $7.0^{\mathrm{a}}$ & $0.4^{b}$ & $0.5^{\mathrm{a}}$ & 0.5 & 0.5 \\
\hline 36 & 76.2 & 76.2 & 2.8 & 2.6 & $2.1^{b}$ & $6.7^{\mathrm{a}}$ & 0.4 & 0.5 & 0.5 & 0.5 \\
\hline 37 & 76.0 & 76.7 & 3.0 & 3.4 & $2.1^{b}$ & $6.9^{a}$ & 0.4 & 0.4 & 0.5 & 0.4 \\
\hline 38 & 75.8 & 74.8 & 2.8 & 3.2 & $2.0^{\mathrm{b}}$ & $7.5^{\mathrm{a}}$ & $0.4^{b}$ & $0.5^{\mathrm{a}}$ & 0.5 & 0.5 \\
\hline 39 & 75.3 & 73.5 & $3.0^{b}$ & $4.0^{a}$ & $2.4^{b}$ & $6.9^{a}$ & 0.4 & 0.4 & 0.4 & 0.5 \\
\hline 40 & 75.1 & 72.3 & 3.3 & 4.0 & $2.6^{b}$ & $6.2^{\mathrm{a}}$ & $0.3^{b}$ & $0.5^{\mathrm{a}}$ & 0.5 & 0.4 \\
\hline 41 & 72.2 & 71.0 & 3.2 & 3.9 & $2.5^{b}$ & $7.2^{\mathrm{a}}$ & 0.4 & 0.4 & 0.5 & 0.6 \\
\hline 42 & 72.8 & 71.1 & 3.9 & 3.9 & $2.8^{\mathrm{b}}$ & $7.2^{\mathrm{a}}$ & $0.3^{b}$ & $0.5^{\mathrm{a}}$ & 0.5 & 0.4 \\
\hline 43 & 70.4 & 69.0 & 4.1 & 4.4 & $3.1^{\mathrm{b}}$ & $6.9^{a}$ & 0.4 & 0.4 & $0.5^{\mathrm{a}}$ & $0.4^{b}$ \\
\hline 44 & 69.1 & 67.3 & $4.1^{b}$ & $5.6^{\mathrm{a}}$ & $3.5^{b}$ & $7.7^{\mathrm{a}}$ & 0.4 & 0.4 & $0.5^{\mathrm{a}}$ & $0.4^{b}$ \\
\hline 45 & 67.0 & 66.8 & 4.4 & 4.7 & $3.2^{\mathrm{b}}$ & $7.4^{\mathrm{a}}$ & 0.4 & 0.4 & 0.5 & 0.5 \\
\hline 46 & 67.2 & 66.4 & $3.8^{\mathrm{b}}$ & $4.7^{\mathrm{a}}$ & $3.1^{\mathrm{b}}$ & $7.2^{\mathrm{a}}$ & 0.4 & 0.4 & 0.5 & 0.5 \\
\hline 47 & 66.8 & 64.4 & 4.2 & 4.6 & $3.1^{\mathrm{b}}$ & $7.1^{\mathrm{a}}$ & 0.4 & 0.5 & 0.5 & 0.5 \\
\hline 48 & 66.8 & 65.0 & 4.7 & 4.7 & $3.6^{b}$ & $7.7^{\mathrm{a}}$ & 0.4 & 0.5 & 0.4 & 0.5 \\
\hline 49 & 65.2 & 62.5 & 4.8 & 5.1 & $3.3^{b}$ & $7.3^{a}$ & 0.4 & 0.4 & 0.5 & 0.5 \\
\hline 50 & 63.2 & 60.3 & $4.3^{b}$ & $5.6^{\mathrm{a}}$ & $3.6^{b}$ & $7.5^{\mathrm{a}}$ & 0.4 & 0.4 & 0.5 & 0.5 \\
\hline 51 & 63.0 & 61.6 & 4.2 & 4.8 & $4.1^{\mathrm{b}}$ & $7.6^{a}$ & 0.3 & 0.4 & 0.4 & 0.5 \\
\hline 52 & 62.1 & 61.4 & 4.0 & 4.8 & $4.2^{b}$ & $7.3^{\mathrm{a}}$ & 0.4 & 0.4 & 0.5 & 0.5 \\
\hline mean & $69.1^{a}$ & $68.3^{b}$ & $3.3^{b}$ & $3.8^{a}$ & $4.2^{b}$ & $8.1^{\mathrm{a}}$ & $0.41^{b}$ & $0.45^{a}$ & 0.5 & 0.5 \\
\hline
\end{tabular}

Different letters on the same line for the same parameter indicate a statistically significant difference (Student's t test, $p<0.05$ ) 
eggs produced, nest dirty eggs, and cracked eggs was significantly higher for the poultry house with handoperated nests at the end of the experimental period $(p<0.05)$.

In the poultry house with mechanical nests, the onset of lay occurred earlier, egg production at the peak of lay was lower, and egg production after the peak was less persistent than in the poultry house equipped with the hand-operated nest (Table 1). The reason for the lower percentage of eggs produced, especially at the beginning of the production period (weeks 28 to 33) in the poultry house with the mechanical nest, may be associated with reproductive problems at the onset of lay. From weeks 25 to 28 , mortality due to egg binding and prolapsed oviduct was $1.5 \%$ higher in the poultry house equipped with the mechanical nest. Mortality due to reproductive problems at the onset of lay, except when health problems occur, is common during this period in most flocks and varies according to management practices, particularly during the breeding period. During the breeding period, hens are kept under feed restriction, which may negatively affect fleshing uniformity of the flock. Both flocks showed adequate weight uniformity, $81 \%$ in the poultry house with the mechanical nest and $84 \%$ in the handoperated one. However, as the population of birds was rather large, the poultry house with the mechanical nest may have lodged a considerable number of hens that were not ready for photostimulation and feeding stimulation, consequently presenting a higher mortality rate than those reared in the poultry house with the hand-operated nest. Flock uniformity was determined by considering the hens that weighed around 10\% of the average weight. According to Abbas et al. (2010), birds that receive early stimulation have higher mortality from reproductive disorders and usually have a lower egg production peak and less persistent egg production after a high performance peak.

Between weeks 25 and 29, there was a significant difference in the percentage of nest dirty eggs, with a higher rate observed in the mechanical nest. This difference was mainly caused by nest height. The first row of nests during mechanical egg collection was placed $20 \mathrm{~cm}$ from the floor, compared with $55 \mathrm{~cm}$ in the hand-operated nest. The closer the nest is to the floor, the easier hens can reach it, especially at the beginning of the breeding period, when the search for nests by the hens is more intense. By visiting the nests too often, hens may dirty their feet with fecal matter and bring it into the nests, soiling the eggs. Cooper \& Appleby (1996) noted that the number of visits to the nests increases before the laying period and at the beginning of the breeding period, and that those hens that lay floor eggs visit the nests more often than those that lay their eggs in the nest. Also, in the poultry house with the mechanical nest, the number of floor eggs is higher than in the hand-operated nest. Another important aspect to be considered is the smaller availability of nests per hen. The poultry house with the mechanical nest contained one nest per 6.25 hens compared to one nest per 4.25 hens in the handoperated nest.

The higher mean percentage value of cracked eggs observed with mechanical collection is mainly due to egg contact between the collecting comb and the hens' feet during collection. The collecting comb was slowly displaced $(2.75 \mathrm{~cm} / \mathrm{s})$, built in $\mathrm{L}$ shape and lined with plastic material in order to protect the eggs during collection. The system needs to be further improved by using softer materials for the manufacture and lining of the comb and by reducing its rotational speed in order to achieve the same results obtained for cracked eggs in the hand-operated nest.

With regard to the laying of floor eggs, the mechanical nest had a worse performance in virtually all weeks. In the first week, the opposite occurred because the mechanical nests were in a lower position than the hand-operated ones, thus aiding hens to find the nests at the beginning of the breeding period. The lack of acceptance of the mechanical nest by most hens may be chiefly attributed to the design of the collection system and to the higher number of hens per nest. This suggests that hens found it more difficult to adapt to the mechanical collection system. The movement of the collecting comb to collect the eggs at the beginning of the breeding period caused many hens to shun the nest. In week 32, this behavior improved, indicating adaptation of the hens to the nests. During the egg production peak, the mechanical nests were overcrowded, especially the lower nests, and two hens ended up laying their eggs in the same nest. This behavior can be attributed to the smaller number of nests available, or to the fact that the mechanical nests were deeper than the hand-operated ones, allowing more hens to enter it. Appleby et al. (1984) reported that there is some hierarchy among hens: dominant hens show preference for specific nests, prompting subordinate hens to seek out another nest when this nest is taken. In a flock of heavy broiler breeders, Holcman et al. (2007) observed that out of $5.1 \%$ of floor eggs, $3.9 \%$ were laid in front of the nest entrance, on the slats, whereas $1.2 \%$ were laid on 
the floor. Those authors found that this difference was associated with the hierarchy among hens regarding the power some of them have over the nests. Four to five hens per nest are recommended (Appleby, 1984). However, some studies have shown that the number of floor eggs decreases with the use of a larger number of hens per nest (Cobb, 2014). Those authors found less than $1 \%$ of floor eggs in broiler breeder flocks using the ratio of one nest for every 6.25 hens. Although the designed mechanical nest resulted in a higher percentage of floor eggs than the hand-operated system, it yielded similar or better results compared with those obtained by the nests currently available on the market. Guerrero et al. (2012), comparing the incidence of floor eggs in mechanical and conventional nest systems, observed rates of $1.6 \%$ for conventional nests and $4.4 \%$ for mechanical nests.

No statistical difference was observed in the percentage of discarded eggs between the two poultry houses, which demonstrates that the designed collection and transport system was similar to the hand-operated one.

No statistical differences were found between the mechanical and hand-operated nests as to the parameters assessed in the hatchery (Table 2), showing that the designed mechanical nest and the change in the position of equipment, required during its installation in the poultry house, did not interfere with hatchability. Also, temperature and moisture were not different between the two types of poultry house during the study period.

In the poultry house equipped with the mechanical nest, although the percentage of floor eggs was higher, the number of employees was reduced by one third in relation to the poultry house equipped with the hand- operated nest. In addition, the mechanical collection of eggs improved the quality of life of employees as less physical effort was required in comparison with manual collection. Relative to the initial investment necessary to install the mechanical nest, the cost virtually doubled compared to that of the hand-operated system. However, in order for the designed mechanical nest to yield similar results to those obtained with the handoperated system, especially concerning the laying of floor eggs, it is necessary to make improvements to the equipment by testing new collecting comb models and collection speed. Therefore, further experiments are required to corroborate the performance of the mechanical collection system developed in the present study.

\section{ACKNOWLEDGMENTS}

I am greatly indebted to Rudimir and Ronievon Karpinski for building the mechanical nest and for granting permission to use their poultry farm for the experiment. I also thank Doux Frangosul for giving me the opportunity to accomplish my PhD studies, and my colleagues Jaison Cadore, Luiz Henrique Didoné, and Darlan Vieira, who helped with the experimental work.

\section{REFERENCES}

Abbas SA, Elseid AAG, Ahmed MKA. Effect of Body Weight Uniformity on the Productivity of Broiler Breeder Hens. International Journal of Poultry Science 2010; 9(3):225-230.

Appleby MC, Mcrae HE. The individual nest box as a super-stimulus for domestic hens. Applied Animal Behaviour Science 1986;15(2):169176.

Appleby MC, Mcrae HE, Duncan NIJH. Choice of social conditions by laying hens. British Poultry Science 1984;25(1):111-117.

Table 2 - Mean percentage of the parameters assessed fortnightly in the hatchery concerning the eggs collected from the hand-operated and mechanical nests during the 28 weeks of study.

\begin{tabular}{lll}
\hline Variable & Hand-operated nest & Mechanical nest \\
\hline \% of eggs with microcracks & 0.46 & 0.52 \\
\% of clear (infertile) eggs & 6.48 & 6.34 \\
\% of emb. mort. 0-7 days of incubation & 3.84 & 4.13 \\
\% of emb. mort. 8-14 days of incubation & 0.62 & 0.789 \\
\% of emb. mort. 15-18 days of incubation & 1.18 & 0.415 \\
\% of emb. mort. 19-21 days of incubation & 1.22 & 0.246 \\
\% mortality - egg shells broken by pecking & 1.82 & 1.20 \\
\% mortality - contaminated eggs & 0.87 & 0.930 \\
\% of hatching & 83.39 & 0.738 \\
\% of chicks with stunting syndrome & 0.52 & 0.59 \\
\hline of eggs contaminated by fungi & 0.00 & 83.35 \\
\hline
\end{tabular}

Emb. mort.- embryo mortality

P-value of two-tailed Student's t test, for comparison the hand-operated and mechanical nests, in relation each variable. 


\section{Development and Performance of a Mechanical Egg Collection System Versus the Hand-Operated Dutch Nest}

Huber HU, Fölsch DW, Stähli U. Influence of various nesting materials on nest site selection of the domestic hen. British Poultry Science 1985;26(3):367-373.

Hurnik JF, Jerome FN, Reinhart BS. Colors as a stimulus for the choice of the nesting site by laying hens. British Poultry Science 1973;14(1):1-8.

Kite VC, Woods RE, Laurent CK. Nesting behaviour of hens in relation to the problem of floor eggs. Reviews in Rural Science 1980;4(3):93-105.

Lay Jr DC, Fulton RM, Hester PY, Karcher DM, Kjaer JB, Mench JA, Mullens BA, Newberry RC, Nicol CJ, O'Sullivan NPO, Porter RE. Hen welfare in different housing systems. Poultry Science 2011;90(1):278-294.

MAFF - Ministry of Agriculture, Fisheries and Food. Deep litter system for layers and breeders. United Kingdom, London: Advisory leaflet; 1982. p.384.

Miuri HK, Harrison PC, Gonyou W. Preferences of hens for shape and size of roosts. Applied Animal Behaviour Science 1990;27(1-2):141-147.

Moller A P, Adriaensen F, Artemyev A, Bańbura J, Barba E, Biard. Variation in clutch size in relation to nest size in birds. Ecology and evolution 2014:4(18):3583-3595

Oliveira B, Rocha Jr CMJ, Bertechini AG. Práticas adotadas para reduzir o número de ovos de cama. Revista Nutritime 2010;7(5):1332-1345.

Peterson VE. Opdraetning af honniker til production of aeg: dryfssistemer, der er alternative til ae glagningsbure. Statens Husdyrbrugsforsg 1989;1-69.

Sander SJE, Wilson JL, Cheng IH, Gibbs PS. Influence of Slat Material on Hatching Egg Sanitation and Slat Disinfection. Journal Applied Poultry Research 2003; 12(1):74-80.

Shimmura T, Maruyama Y, Fujino S, Kamimura. Persistent effect of broody hens on behaviour of chickens. Animal Science Jounal 2015; 86(2):214220 .

Scholz B, Kjaer JB, Schrader L. Analysis of landing behaviour of three layer lines on different perch designs. British Poultry Science 2014;55(4):419426.
Holcman A, Malovrh S, Stuhec I. Choice of nest by hens of three lines of broiler breeders. British Poultry Science 2007;48(3):284-290. 